Case Report

\title{
Transitory Spontaneous Remission of Myelodysplasia in an Elderly Man while Receiving Intravesical Bacillus Calmette- Guérin for Bladder Cancer: A Case Report and Review of the Literature
}

\author{
Nigel P. Murray $\mathbb{D}^{1,2}$ Cynthia Fuentealba, ${ }^{3}$ Isidora Salazar, ${ }^{4}$ Aníbal Salazar ${ }^{1 D},{ }^{3}$ \\ Marco Antonio Lopez, ${ }^{5}$ and Simona Minzer \\ ${ }^{1}$ Consultant Hemologist, Depto. Medicine, Hospital de Carabineros de Chile, Simón Bolívar 2200, Nuñoa 7770199, \\ Santiago, Chile \\ ${ }^{2}$ Professor Hematology, Faculty of Medicine, University Finis Terrae, Av Pedro de Valdivia 1509, Providencia, Santiago, Chile \\ ${ }^{3}$ Consultant Urologist, Urology Service, Hospital de Carabineros de Chile, Simón Bolívar 2200, Ñuñoa 7770199, Santiago, Chile \\ ${ }^{4}$ Medical Student, Faculty Medicine, University Los Andes, Monseñor Alvaro del Portillo 12,455 Las Condes, Santiago, Chile \\ ${ }^{5}$ Physician, General Medicine, Hospital de Carabineros de Chile, Simón Bolívar 2200, Nuñoa 7770199, Santiago, Chile
}

Correspondence should be addressed to Nigel P. Murray; nigelpetermurray@gmail.com

Received 20 September 2018; Accepted 21 October 2018; Published 11 November 2018

Academic Editor: Yusuke Shiozawa

Copyright (c) 2018 Nigel P. Murray et al. This is an open access article distributed under the Creative Commons Attribution License, which permits unrestricted use, distribution, and reproduction in any medium, provided the original work is properly cited.

\begin{abstract}
Myelodysplasia is a clonal disorder characterized by progressive cytopenias. Intravescial BCG is standard immunotherapy for superficial bladder cancer. We present a patient with transfusion-dependent myelodysplasia whose blood counts normalized during treatment with intravesical BCG for bladder cancer. After finishing treatment, the patient became transfusion dependent once more. We discuss possible mechanisms to explain this case report.
\end{abstract}

\section{Introduction}

Intravesical treatment with Bacillus Calmette-Guérin (BCG) has been a standard adjuvant therapy for non-muscleinvasive bladder cancer for the last $40-50$ years [1]. BCG is a live attenuated strain of Mycobacterium bovis, and although minor side effects are common, serious side effects occur in less than $5 \%$ of patients, of which most are local and present early after treatment [2]. Systemic side effects have included infection, autoimmune disorders, and pancytopenia $[3,4]$.

Although spontaneous remission of acute myeloid leukemia was first reported in 1878 [5], it is a rare event and usually of short duration, of the approximately 100 cases reported before the use of chemotherapy in the 1950s; only 14 eligible cases fulfilling modern criteria have been reported up until 2014 [6]. Fewer cases have been reported in patients with myelodysplasia, the majority in children or young people $<20$ years and in the presence of monosomy 7 [7-9]. In a large retrospective series of 564 adult patients with myelodysplasia, spontaneous remission was reported in 9 $(1.6 \%)$ of cases [10]. We report the case of a 69-year-old man with myelodyplasia whose full blood count became normal during treatment with intravesical BCG for bladder cancer.

\section{Clinical Case}

A 69-year-old man presented in 2008 with a macrocytic anemia; the hemoglobin level was $10.2 \mathrm{~g} / \mathrm{dl}(13.0-18.0 \mathrm{gr} / \mathrm{dl})$, MCV (mean corpuscular volume) $114 \mathrm{fl}(80-97 \mathrm{fl})$, the white cell count including differential count was normal, the platelet count was 155,000 (normal), and the reticulocyte 
count was decreased $(0.7 \%)$ in the presence of an anemia. The serum B12, serum folate, serum thyroid-stimulating hormone level, and liver function tests were normal. A bone marrow biopsy was consistent with refractory anemia and blasts $<5 \%$. He was treated with a trial of anabolic steroids without success.

In 2011, the patient was referred to the hematology department, with a hemoglobin level of $7.0 \mathrm{gr} / \mathrm{dl}, \mathrm{MCV} 123 \mathrm{fl}$, a platelet count of 50,000, and reticulocyte count of $0.9 \%$. At this time, serum B12, serum folate, serum TSH, and liver function tests were normal. The ferritin was $446 \mathrm{ng} / \mathrm{ml}$ (increased), percent saturation of transferrin was 31.8 (normal), a serum protein electrophoresis was normal, urine analysis was normal, and serum PSA level was $0.699 \mathrm{ng} / \mathrm{ml}$ (the patient had previously undergone a transurethral resection for benign prostatic hyperplasia in 1996). Repeat bone marrow biopsy, after red cell and platelet transfusions, revealed a hypercellular bone marrow, with dysplastic features, including micromegakaryocytes and blasts $<5 \%$. Cytogenetic study revealed a normal karyotype. The diagnosis remained that of myelodysplasia of refractory anemia (Figure 1).

To alleviate the symptoms of anemia, monthly transfusions of red cells were needed to maintain the hemoglobin level above $8.0 \mathrm{gr} / \mathrm{dl}$. The platelet count continued to decrease but apart from some superficial bruising and platelet transfusions were not required.

In October 2013, the patient noted painless macroscopic hematuria lasting for two days, his full blood count showed a hemoglobin level of $7.5 \mathrm{gr} / \mathrm{dl}$; a platelet count of 13,000 , a normal white cell count, and tests of the coagulation showed a normal prothrombin and activated partial thromboplastin times.

Urine analysis confirmed hematuria, and urine culture was negative for infection. An excretion CT scan of the urinary system revealed a lobulated lesion in the region of the left ureteral meatus with a diameter of $16 \mathrm{~mm}$ (Figures 2 and 3).

With transfusions of red cells and platelets, the patient underwent a diagnostic cystoscopy, which revealed five bladder tumors (Figure 4).

With transfusional support of both red cells and platelets, a TUR-B (transurethral resection bladder tumor) was performed, with resection of the five tumors and electrocoagulation of the tumor bed. The largest tumor had a diameter of $1 \mathrm{~cm}$ and was located at the left urethral opening. Pathological analysis revealed a low-grade superficial urothelial papillary carcinoma without evidence of bladder wall infiltration.

After resection of the tumor, the patients' transfusional requirements decreased, but he remained transfusion dependent. A second cystoscopy two months later showed the tumor resection scar; in the trigonal area, a small papillary growth was resected, and the area around the scar was electrocauterized. The growth was a superficial low-grade papillary carcinoma.

Intravesical BCG, weekly for 6 weeks, then two-weekly for 4 doses, and then monthly for 1 year, starting in March 2015 and finishing in July 2016. Repeat cystoscopy in October 2015 and February 2017 showed no tumor recurrence.
While receiving $\mathrm{BCG}$, the hemoglobin and platelet counts increased, achieving normal levels and the patient became transfusion independent. One month after completing BCG treatment, both the hemoglobin level and platelet counts were decreasing, and six months later, the patient had a hemoglobin level of $8.5 \mathrm{gr} / \mathrm{dl}$, MCV 113, and a platelet count of 26,000 (Figure 5). A repeat bone marrow biopsy showed a hypocellular bone marrow, with between $30 \%$ and $50 \%$ of the intertrabecular spaces being occupied by hematopoietic tissue (Figure 6). There was a significant decrease in the erythroid precursors $(<10 \%)$ and megakaryocytes. There was no evidence of fibrosis or infiltration of the bone marrow with a CD34 count of less than 5\%.

Immunohistochemistry detection of cells staining positive for pancytokeratin and EpCAM was negative, indicating the lack of micrometastatic disease (Figure 7).

Since February 2017, the patient is once again transfusion dependent for packed red cells.

\section{Discussion}

Myelodysplasia is the result of a clonal stem cell defect, which may be accompanied by various cytogenetic abnormalities. It is a progressive disease mainly affecting the elderly, and in the majority of patients, the treatment is transfusional support with red cells and/or platelets to maintain the quality of life.

The clinical findings in this case were consistent with myelodysplasia with progressive anemia, requiring chronic transfusions of red cells to maintain the quality of life. Platelet transfusions were on a required basis according to hemorrhagic events and not on a prophylactic basis. The initial macroscopic hematuria was considered to be in the context of a possible urinary infection and the severe thrombocytopenia, which in myelodysplasia is associated with platelet dysfunction.

The final diagnosis was multiple foci of bladder cancer, which was treated according to the recommended clinical guidelines of resection and immunotherapy with BCG.

The case presents two questions, Why did transfusion requirements decrease after tumor resection and were unnecessary during BCG treatment? Secondly, why did the hemoglobin and platelet counts return to baseline levels after finishing BCG treatment and why was there a change in the cellularity in the bone marrow?

(1) Decreased transfusional requirements after tumor resection: a possible reason to explain the recuperation of the red cells and platelets after tumor resection is that, by removing the tumor, there was no further bleeding (including microscopic). The decreased consumption of platelets and decreased loss of red cells resulted in increased levels of both blood components. The limited capacity of the myelodysplastic bone marrow to increase production due to bleeding resulted in a more severe anemia and thrombocytopenia.

However, this theory falls short because it does not explain the rapid decrease in red cell and platelet levels after 


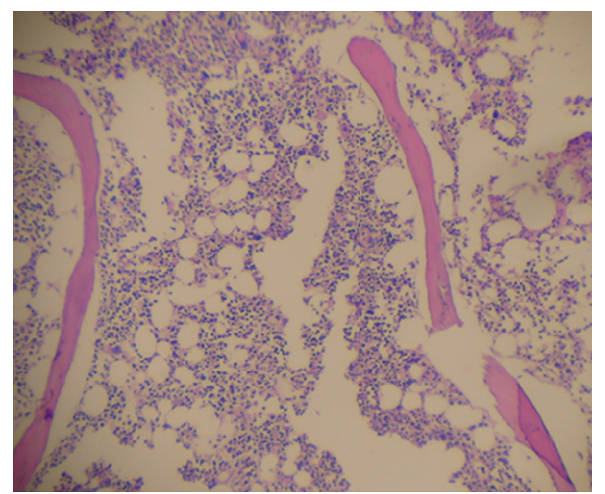

(a)

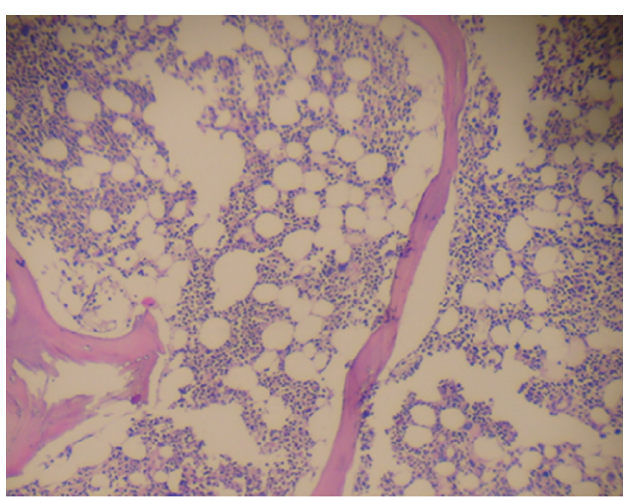

(b)

FIGURE 1: First bone marrow biopsy showing normo/hypercellularity.

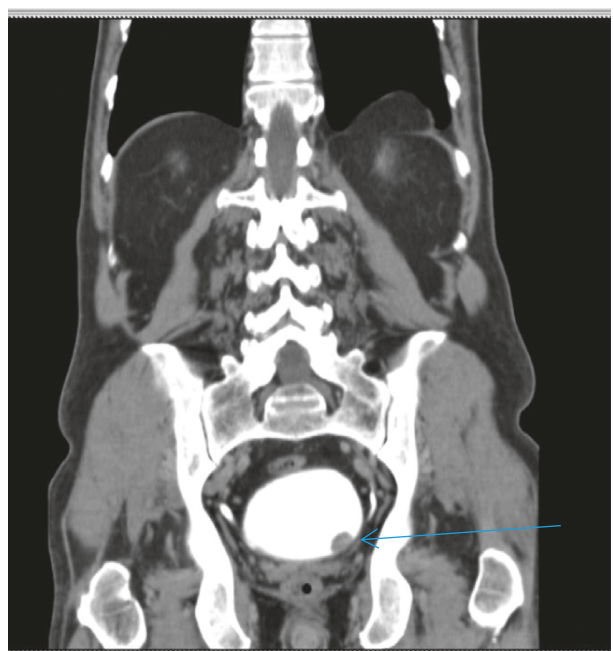

(a)

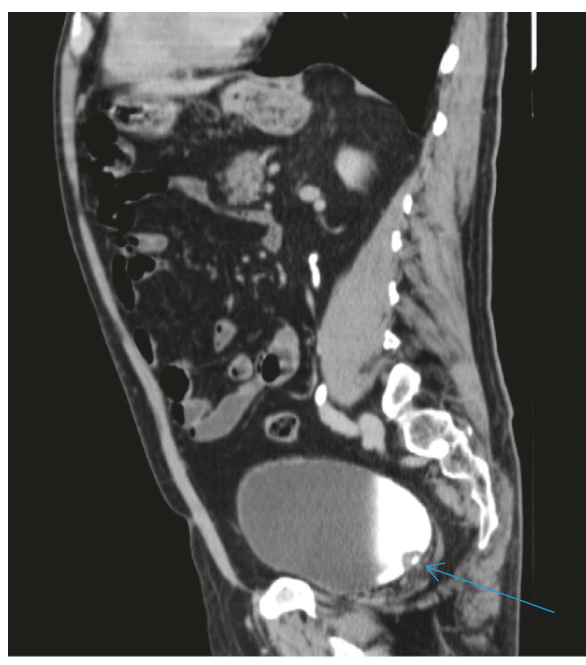

(b)

FIgURE 2: Coronal sections Uro-CT scan with contrast showing filling defect (arrows).

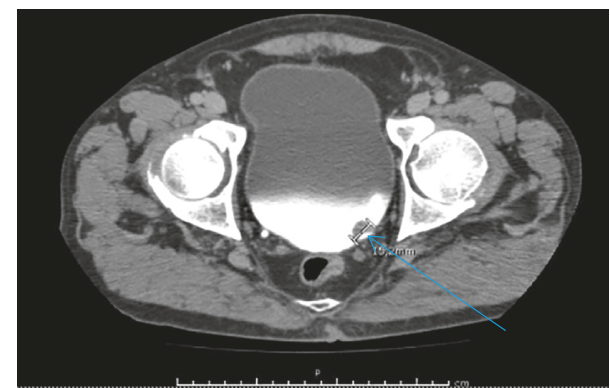

FIGURE 3: Sagittal section Uro-CT scan showing proliferative lesion left ureteral meatus (arrow).

BCG therapy, in the light of tumor remission and without evidence of bone marrow infiltration by tumor cells. Nor does it explain the change from a hypercellular to a hypocellular bone marrow.

Bladder cancer has been associated with a paraneoplastic leukemoid reaction, there being a leukocytosis $[11,12]$. Bladder cancer has also been associated with thrombocytosis, alone [13] or in combination with the leukemoid reaction [14]. The leukocytosis is thought to be due to production of granulocyte colony stimulating factor by the tumor $[15,16]$. However, in the case reported, the platelet count increased after tumor resection.

(2) Effect of intravesical BCG therapy: with the use of BCG, the hemoglobin and platelet counts increased to normal levels, the maximum platelet count being 317,000, and maximum hemoglobin level of $13.7 \mathrm{gr} / \mathrm{dl}$ (although the MCV remained high). These levels were maintained throughout the year-long period, decreasing to transfusion-dependent levels within 3 months of finishing treatment.

The use of intravescial BCG has been reported to be associated with systemic autoimmune diseases, such as cyroglobulinemia vasculitis [17], autoimmune retinopathy [18], Henoch-Schonlein purpura [19], and haemophagocytic syndrome [20]. BCG has also caused a pancytopenia due to bone marrow infection, which may be delayed up to 


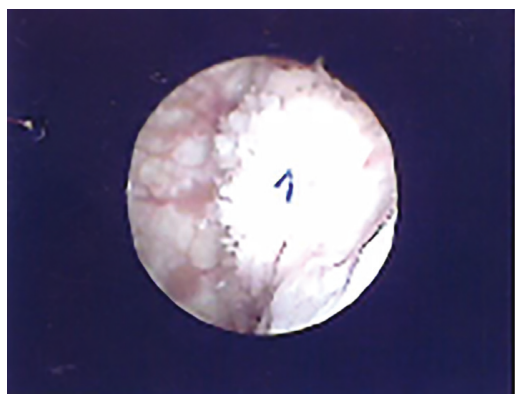

(a)

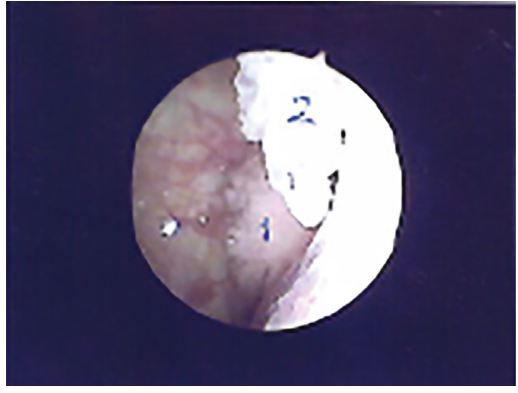

(b)

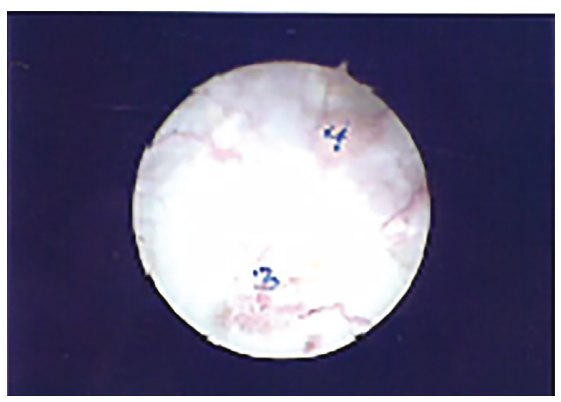

(c)

Figure 4: Four tumors seen at initial cystoscopy.

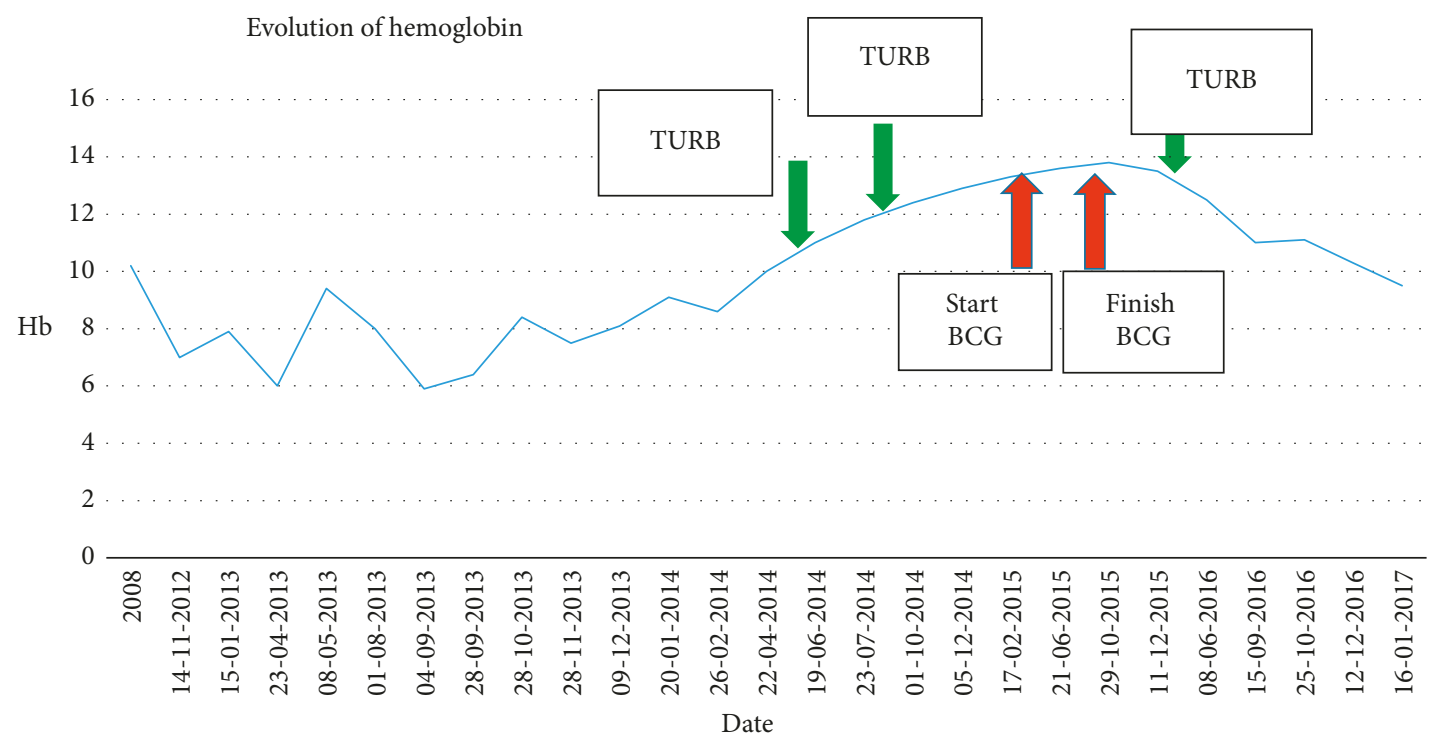

$-\mathrm{Hb}$

(a)

Evolution of platelets

(b)

Figure 5: Trends in hemoglobin levels and platelet counts with time. 


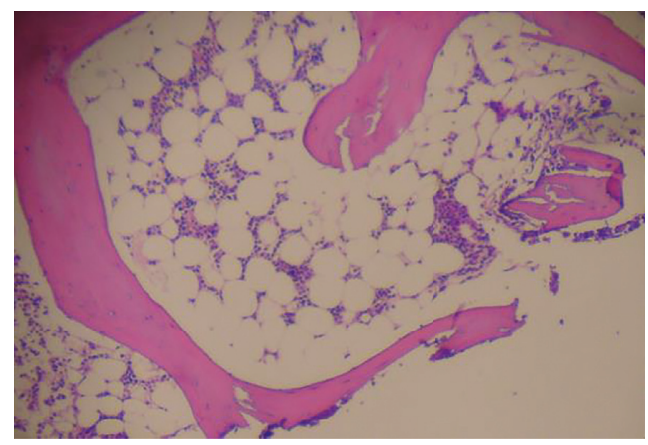

(a)

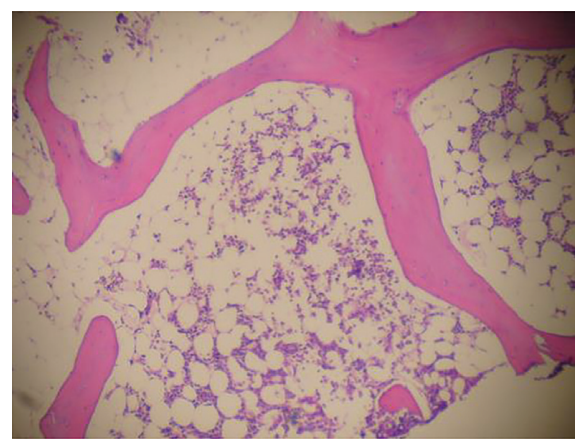

(b)

FIGURE 6: Repeated bone marrow biopsy showing marked decreased cellularity in comparison with the first biopsy.

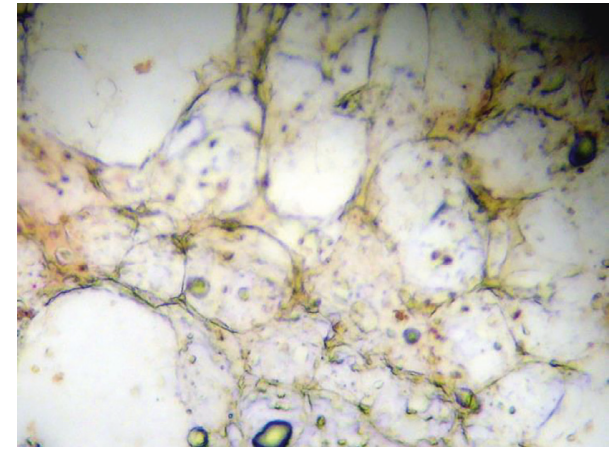

FiguRE 7: Bone marrow, negative for micrometastasis.

two years post-treatment $[4,20]$. This highlights that intravesical BCG may produce systemic side-effects. However, these mechanisms do not explain the normalization of the full blood count and zero transfusional requirements during BCG therapy and subsequent worsening of the anemia and thrombocytopenia after finishing the treatment.

The mechanisms for spontaneous remissions in acute myeloid leukemia are unknown; however, severe systemic infections often precede the remission. They are most often reported with bacterial infections [21-23] or fungal infections such as Aspergillus [24] or Pneumocystis [25]. It has been proposed that activation of the immune system with increased levels of tumor necrosis factor- $\alpha$, interferon- $\gamma$, and interleukins IL-2, as well as monocytes, macrophages, natural killer cells, dendritic cells, and B- and T-lymphocytes [26]. Macrophages, NK cells, and T-lymphocytes are activated, and TLR-activated regulatory $\mathrm{T}$-cells are prevented from inhibiting specific cytotoxic T-cells [27]. Prolonged exposure to TLR agonists sensitizes tumor cells to killing by immune mechanisms, especially cytotoxic $\mathrm{T}$-cells. In vitro leukemic cells become more sensitive to cytotoxic T-cells after several days of activation by TRL agonists [28].

BCG stimulates TRL2 and TRL4 via its mycobacterial components, including cell wall skeleton and peptidoglycan. It also stimulates TRL9 via its bacterial DNA [29, 30]. BCG stimulates TRAIL/Apo-2L secretion from neutrophils, as do TRL2 and TRL4 agonists. TRAIL/Apo-2L recruits macrophages and cytotoxic T-cells and may be a mechanism of its anticancer effect [31].

This could be a possible mechanism for the changes seen during BCG treatment, the decrease in clonal myelodysplastic cells permitting more normal hematopoiesis. This decrease in myelodysplastic cells would also explain the change from a hypercellular to hypocellular bone marrow. After finishing treatment, there was no longer TRL agonist stimulation permitting a slow recuperation of the myelodysplastic clone and return to pretreatment levels of hemoglobin and platelet counts. The fact that there was no evidence of tumor relapse supports the hypothesis of an effect of BCG therapy rather than an effect of the bladder cancer. The patient had no evidence of systemic infection or inflammatory disease during the remission period.

A second possibility is the use of blood transfusions; cytotoxic antibodies against leukemic cells have been previously described [32] or transfused allogeneic lymphocytes causing a "graft versus leukemia effect" [33].

However, in cases of spontaneous remission in patients with myelodysplasia, there was not an association with sepsis [10]. In this group of patients, the median time from diagnosis was 18 months with a median duration of transfusional support was 15 months. In the case reported, the patient had been diagnosed seven years previous to the BCG admission, the remission lasted approximately the same time period as BCG treatment. The inference being that the BCG caused the transient remission.

In summary, a patient with transfusion-dependent myelodysplasia was diagnosed with bladder cancer. With transfusional support, the tumor was successfully resected, requiring two operations. During the administration of intravesical BCG therapy, the full blood count normalized and transfusions were not required. We postulate that a TRL agonist effect was produced by the BCG, affecting clonal myelodysplastic stem cells, permitting the normalization of the full blood count. After cessation of BCG therapy, the full blood count returned to pretreatment values and transfusion dependence.

\section{Conflicts of Interest}

The authors declare that they have no conflicts of interest. 


\section{Acknowledgments}

The authors acknowledge Mrs. Ana Maria Palazuelos for her help in writing this manuscript.

\section{References}

[1] R. J. Sylvester, A. P. M. Van der Meijden, and D. L. Lamm, "Intravesical bacillus Calmette-Guerin reduces the risk of progression in patients with superficial bladder cancer: a meta-analysis of the published results of randomized clinical trials," Journal of Urology, vol. 168, no. 5, pp. 1964-1970, 2002.

[2] D. L. Lamm, A. P. M. Van der Meijden, A. Morales et al., "Incidence and treatment of complications of Bacillus Calmette-Guerin intravesical therapy in superficial bladder cancer," Journal of Urology, vol. 147, no. 3, pp. 147-596, 1992.

[3] D. N. Nan, M. Fernandez-Ayala, C. Garcia-Ibarbia et al., "Henoch-schonlein purpura after intravesical administration of BCG," Scandinavian Journal of Infectious Diseases, vol. 37, no. 8, pp. 613-615, 2006.

[4] P. Dammert, Z. Boujaoude, W. Rafferty, and J. Kass, "Fever of unknown origin and pancytopenia caused by culture proven delayed onset disseminated BCG infection after intravesical instillation," BMJ Case Reports, vol. 2013, no. 1, article bcr2013008949, 2013.

[5] C. Eisenlohr, "Leucaemia lienalis: lymphatic and medularis mit multiplen Gehirnnervenlahmungen," Virchows Arch A, vol. 73, pp. 56-73, 1878.

[6] P. Vachhani, J. H. Mendler, A. Evans et al., "Spontaneous remission in an older patient with relapsed FLT3 ITD mutant AML," Case Reports in Hematology, vol. 2016, Article ID 1259759, 7 pages, 2016.

[7] T. M. Parker, R. J. Klaassen, and D. L. Johnston, "Spontaneous remission of myelodysplastic syndrome with monosomy 7 in a young boy," Cancer Genetics and Cytogenetics, vol. 182, no. 2, pp. 122-125, 2008.

[8] W. Scheurlen, A. Borkhardt, J. Ritterbach et al., "Spontaneous hematological remission in a boy with myelodysplastic syndrome and monosomy 7," Leukemia, vol. 8, no. 8, pp. 1435-1438, 1994.

[9] E. Benaim, E. V. Hvizdala, P. Papenhausen, and L. C. Moscinski, "Spontaneous remission in monosomy 7 myelodysplastic syndrome," British Journal of Haematology, vol. 89, no. 4, pp. 947-948, 1995.

[10] M. C. Petti, R. Latagliata, M. Breccia et al., "Spontaneous remission in adult patients with de novo myelodysplastic syndrome: a possible event," Haematologica, vol. 86, no. 12, pp. 1277-1280, 2001.

[11] K. Stav, D. Leibovici, I. Yoram, and A. Lindner, "Leukemoid reaction associated with transitional cell carcinoma," IMAJ, vol. 4, no. 3, pp. 223-224, 2002.

[12] H. S. Chung, B. S. Shin, H. S. Yu et al., "Leukemoid reaction, a rare paraneoplastic syndrome in urothelial cell carcinoma: is it an indicator of a poor prognosis?," Korean Journal of Urological Oncology, vol. 13, no. 3, pp. 134-137, 2015.

[13] J. K. Bennett, J. K. J. Wheatley, K. N. Walton et al., "Nonmetastatic bladder cancer associated with hypercalcemia, thrombocytosis and leukemoid reaction," Journal of Urology, vol. 135, no. 1, pp. 47-48, 1986.

[14] N. L. Block and W. F. Whitmore Jr., "Leukemoid reaction, thrombocytosis and hypercalcemia associated with bladder cancer," Journal of Urology, vol. 110, no. 6, pp. 660-663, 1973.
[15] T. Asano, S. Morimoto, Y. Kitami et al., "Bladder cancer producing granulocyte-stimulating factor (G-CVSF): a case report," Hinyokika Kiyo, vol. 48, no. 8, pp. 495-498, 2002.

[16] T. Yoshino and K. Yoneda, "Urinary bladder cancer producing granulocyte-colony stimulating factor: a case report and review of the literature," Hinyokika Kiyo, vol. 54, no. 12, pp. 775-778, 2008.

[17] B. Granel, J. Serratrice, P. E. Morange et al., "Cryoglobulinemia vasculitis following intravescial instillations of BCG," Clinical and Experimental Rheumatology, vol. 22, no. 4, pp. 481-482, 2004.

[18] S. Sharan, C. E. Thirkill, and J. R. Grigg, "Autoimmune retinopathy associated with intravesical BCG therapy," British Journal of Ophthalmology, vol. 89, no. 7, pp. 927-928, 2005.

[19] S. Misra, A. Gupta, A. Symes, and J. Duncan, "Haemophagocytic syndrome after intravesical BCG," Scandinavian Journal of Urology, vol. 48, no. 3, pp. 328-330, 2014.

[20] J. Nemeth, B. Stoiser, H. M. Winkler et al., "Bone marrow infection with BCG after intravesical immunotherapy," Wiener klinische Wochenschrift, vol. 120, no. 3-4, pp. 121-123, 2008.

[21] N. Ifrah, J. M. James, F. Viguie et al., "Spontaneous remission in adult acute leukemia," Cancer, vol. 56, no. 5, pp. 1187-1190, 1985.

[22] M. Mitterhauer, M. Fritzer-Szekeres, G. Mitterbauer et al., "Spontaneous remission of acute myeloid leukemia after infection or blood transfusion associated with hypergammaglobulinemia," Annals of Hematology, vol. 73, no. 4, pp. 189-193, 1996.

[23] A. Delmer, E. Heron, J. P. Marire et al., "Spontaneous remission in acute myeloid leukemia," British Journal of Haematology, vol. 87, no. 4, pp. 880-882, 1994.

[24] A. Tzankov, C. Ludescher, H. C. Duba et al., "Spontaneous remission in a secondary acute myelogenous leukaemia following invasive pulmonary aspergillosis," Annals of Hematology, vol. 80, no. 7, pp. 423-425, 2001.

[25] A. Fassas, L. Sakellari, A. Anagnostopoulos, and R. Saloum, "Spontaneous remission of acute myeloid leukemia in a patient with concurrent Pneumocystis carinii pneumonia," Nouvelle revue Française D'Hematologie, vol. 33, no. 5, pp. 363-364, 1991.

[26] B. D. MaywaldOJ. Bergmann et al., "Spontaneous remission in adult acute myeloid leukemia in association with systemic bacterial infection-case report and review of the literature," Annals of Hematology, vol. 83, no. 3, pp. 189-194, 2004.

[27] B. Sprangers, B. Van Wijmeersch, S. Fevery, M. Waer, and A. D. Billiau, "Experimental and clinical approaches for optimization of the graft versus leukemia effect," Nature Clinical Practice Oncology, vol. 4, no. 7, pp. 404-414, 2007.

[28] C. V. Ichim, "Revisiting immunosurveillance and immunostimulation: implications for cancer immunotherapy," Journal of Translational Medicine, vol. 3, no. 1, p. 8, 2005.

[29] J. Uehori, M. Matsumoto, S. Tsuji et al., "Simultaneous blocking of human TRL2 and 4 suppresses myeloid dendritic cell activation induced by Mycobacterium bovis BCG peptidoglycan," Infection and Immunity, vol. 71, no. 8, pp. 42384249, 2003.

[30] T. Tokunaga, H. Yamamoto, S. Shimada et al., "Antitumor activity of DNA fraction from Mycobacterium bovis BCG. I. Isolation, physiochemical characterization and anti-tumour activity," Journal of the National Cancer Institute, vol. 72, no. 4, pp. 955-962, 1984.

[31] T. J. Kemp, A. T. Ludwig, J. K. Earel et al., "Neutrophil stimulation with Mycobacterium bovis bacillus Calmette- 
Guerin (BCG) results in the release of functional soluble TRAIL/Apo-2L," Blood, vol. 106, no. 10, pp. 3474-3482, 2005.

[32] J. F. Dore, C. Guibout, J. Bertoglio, and A. Liabeuf, "Cytotoxic antibodies to human leukaemia cells in normal human sera," Biomedicine, vol. 25, no. 10, pp. 382-384, 1976.

[33] H. J. Kolb, A. Schattenberg, J. M. Goldman et al., "Graft versus leukemia effect of donor lymphocyte transfusions in marrow grafted patients. European Group for Blood and Marrow Transplantation Working Party Chronic Leukemia," Blood, vol. 86, pp. 2041-2250, 1995. 


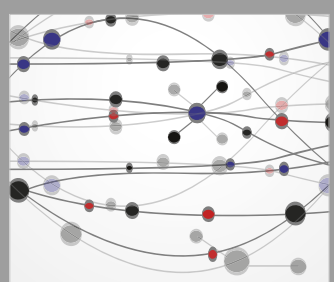

The Scientific World Journal
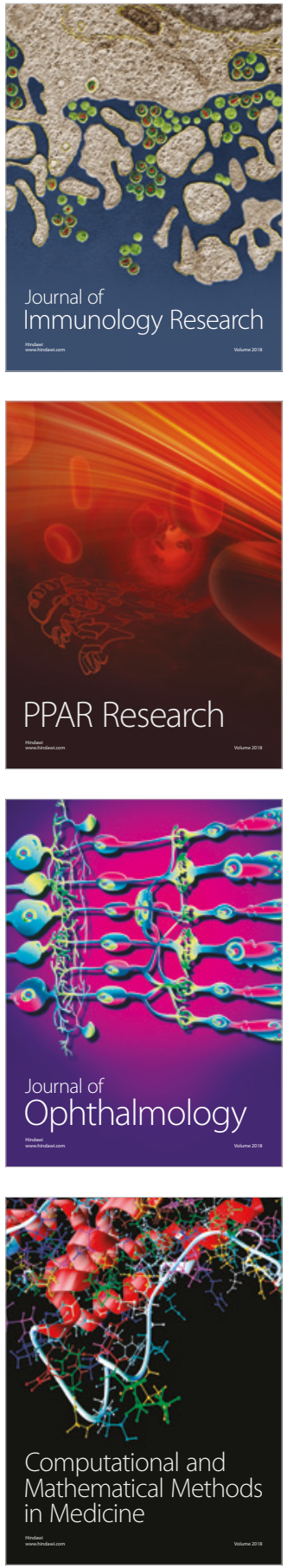

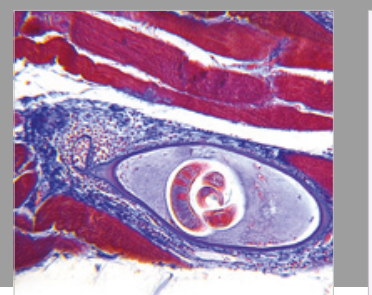

Gastroenterology Research and Practice

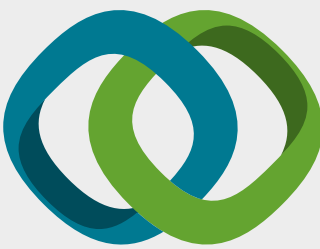

\section{Hindawi}

Submit your manuscripts at

www.hindawi.com
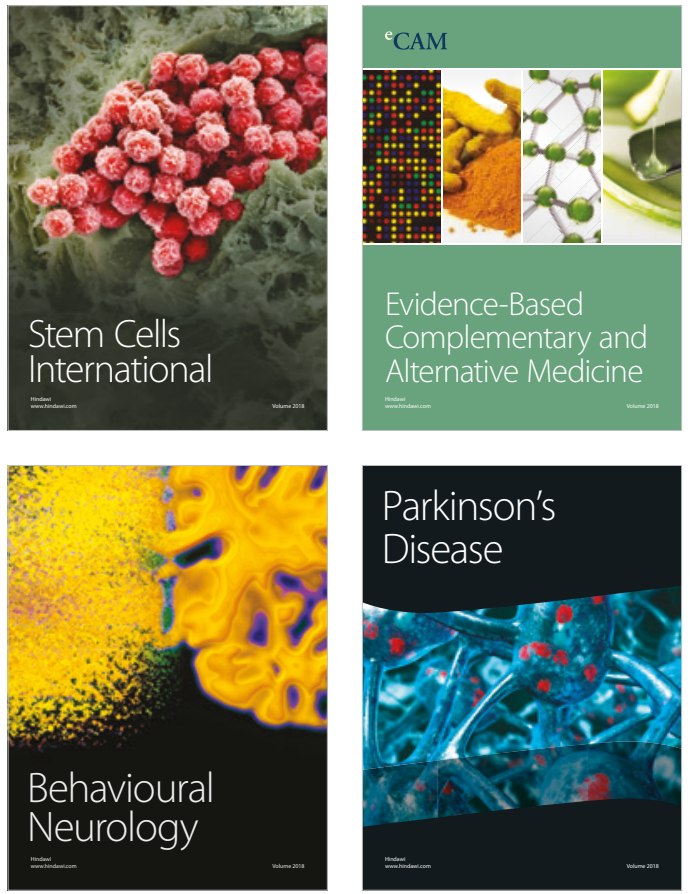

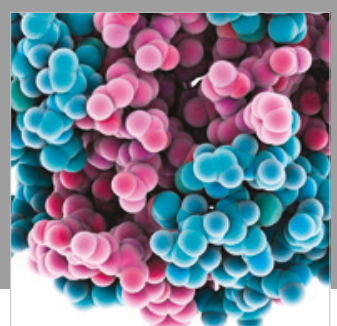

ournal of

Diabetes Research

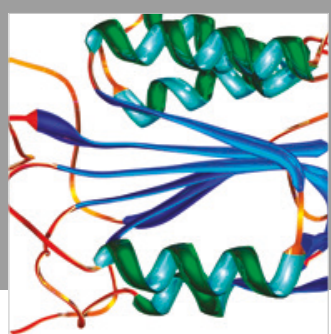

Disease Markers
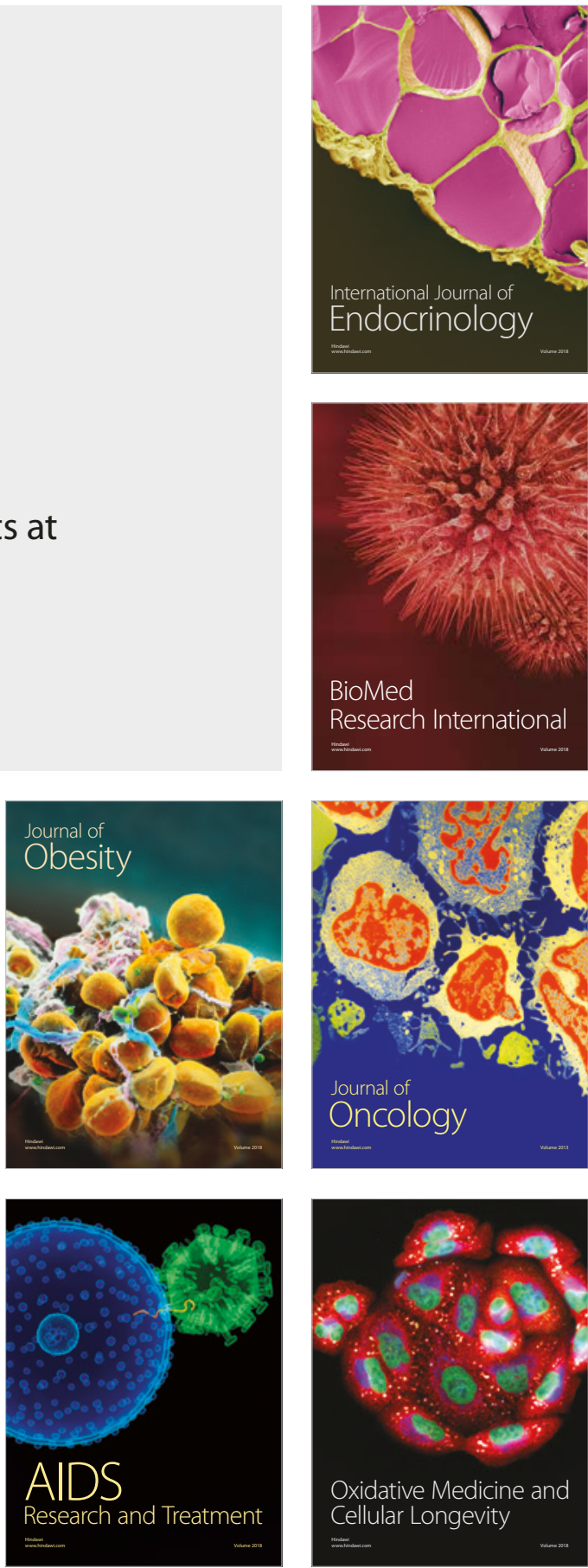